\title{
Rebuilding of an ancient castle including a base-isolated museum hall
}

\author{
S. Sorace ${ }^{1} \&$ G. Terenzi ${ }^{2}$ \\ ${ }^{1}$ Department of Civil Engineering, Udine University, Italy \\ ${ }^{2}$ Department of Civil and Environmental Engineering, Florence, Italy
}

\begin{abstract}
A design hypothesis to rebuild the main wing of the medieval castle of Prampero, devastated by a violent earthquake in Friuli in 1976, is presented in this paper. The intervention suggests that the building be used as a museum to exhibit the artistic heritage of the owners. This new destination prompted some architectural rearrangements of the interiors of the building as compared to its original configuration, while preserving the global volume and the interstory heights, as well as the outer appearance of the castle, including its façades, the roof and all finishes. The structural design includes some updated traditional solutions for the masonry walls, the wooden floors and the roof. At the same time, a non-conventional solution is adopted for the floor accommodating the main exhibition hall, consisting in the incorporation of a base isolation seismic protection system. Details of the design analyses carried out, with special regard to the numerical enquiry developed on the base-isolated floor, are provided in this paper. Selected drawings of the technical solutions adopted are also presented.

Keywords: historical buildings, rebuilding, structural rehabilitation, seismic protection, art contents, base isolation.
\end{abstract}

\section{Introduction}

A number of medieval castles were seriously damaged, if not partially or totally destroyed, by the earthquake that hit the region of Friuli, in north-eastern Italy, in 1976. Generally belonging to private owners, several of these monumental buildings were not rebuilt, and have remained in their post-earthquake conditions until the present day. In some cases, minor stabilization and strengthening works 
of the ruins were carried out, in order to preserve the surviving parts of basements, perimeter walls, towers, chapels, communication trenches, loggias, galleries, etc. This is also the case of the Castle of Prampero, sited in Manzano, near Udine, which is one of the oldest and most famous examples of a medieval stronghold in the region of Friuli. Only recently, after a long time of neglect, the first rebuilding intervention was started in the northern tower, and has just been completed. A second stage is expected soon, and will concern the central portion of the castle. Several different hypotheses were formulated for the use of this area, when it will be rebuilt. One of these hypotheses, developed in this paper, suggests it will be used as a museum, where the art collections of the owners can be exhibited.

Based on this assumption, a complete architectural and structural rebuilding design of this main portion of the castle is presented, and namely: a design of the new masonry walls, wooden floors and roof; a seismic analysis of the new structures; a re-organization of the interiors, aimed at removing any architectural barriers on all floors, and creating a large exhibition hall on the ground floor. Because the hall is expected to exhibit two important statues of the owners' collection, a seismic isolation solution was formulated for the relevant floor. This represents a novel strategy for the advanced seismic protection of museum buildings, since base isolation of single statues and artistic objects, rather than of an entire bearing floor, have been generally proposed in this field. The structural analyses developed for this case study also include a computational investigation of the possible rocking effects of the statues, whose complete elimination was among the objectives assumed in the design of the base isolation system.

\section{Rebuilding design hypothesis}

The architectural renderings of the castle before the 1976 earthquake, and in its current conditions, are drawn in Figures 1 and 2, respectively. As highlighted in the second figure, only the farthest wing, named northern tower, was rebuilt, whereas the remaining zones are either totally destroyed, or reduced to a heap of ruins. Only some stumps of the ground floor and walls on the first floor also remain for the central portion of the castle, adjacent to the northern tower.
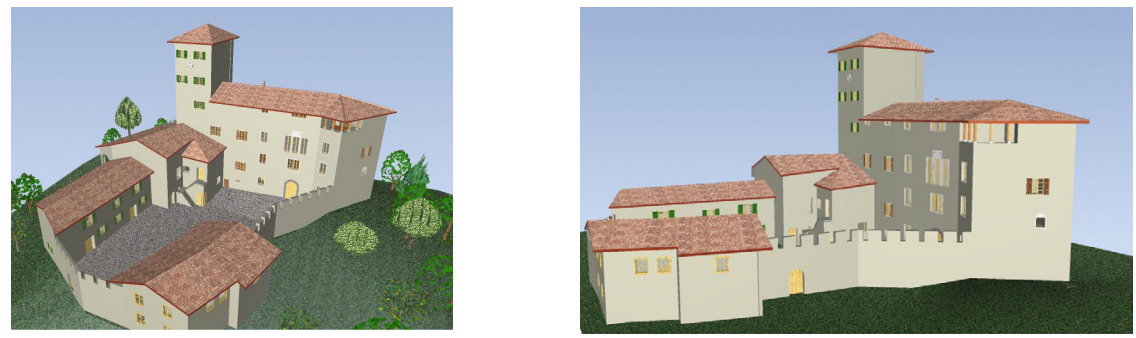

Figure 1: Renderings of the castle before the 1976 earthquake. 

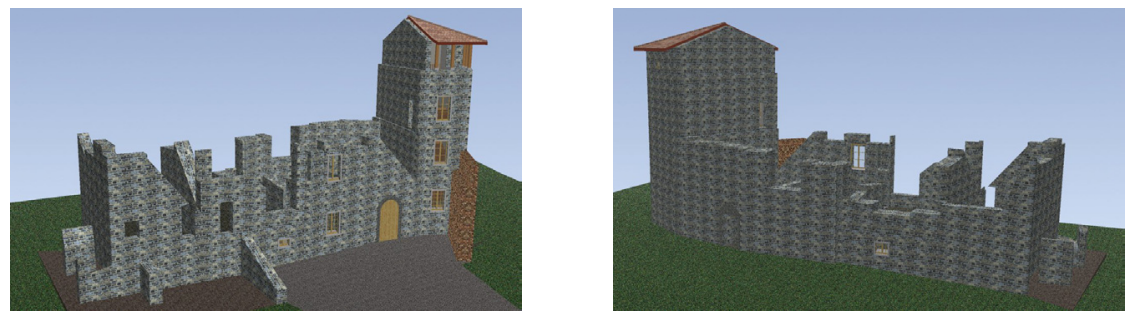

Figure 2: Renderings of the castle in its current condition.

A global photographic view of the northern tower during the restoration works, and detailed views of its front, including the survived main door of the central part of the castle, and the stone blocks already arranged to be connected to the perimeter walls of the central zone, when it will be rebuilt, are shown in Figure 3. It can be observed that the original stones recovered from the collapsed walls will be used for reconstruction, in combination with high-strength hydraulic-lime mortars.
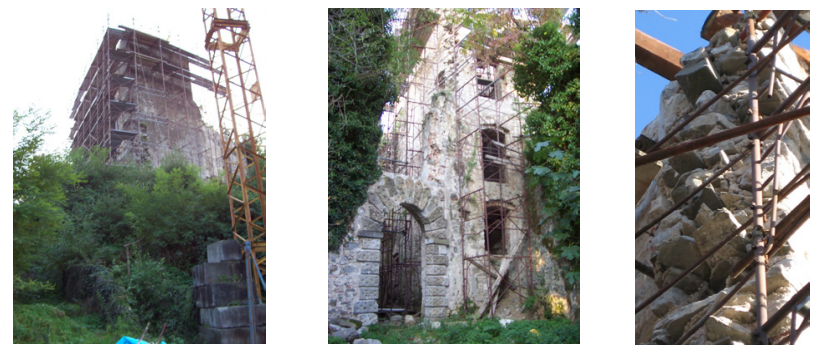

Figure 3: Photographic views of the northern tower during the restoration works.

The rebuilding hypothesis of the central part is illustrated in Figure 4, where the renderings of the façade and the longitudinal cross section of the building are drawn.
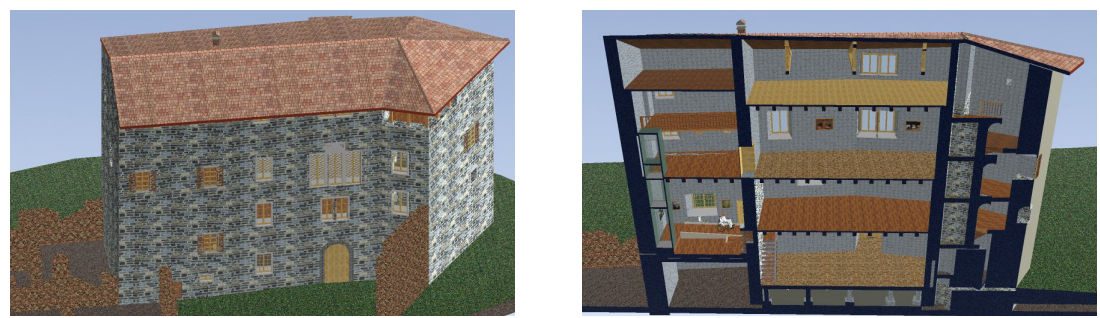

Figure 4: Rebuilding hypothesis of the central portion of the castle. 
Two transversal sections of the largest rooms, referred to the pre-existing and design configurations, are reported in Figure 5. A comparison of the two views illustrates the main internal change introduced in the design, which consists in the elimination of the original median wall on the two lower stories, so as to obtain two single exhibition halls at these levels. This choice implies a rotation of the plot of the wooden floors to reach a new maximum net span slightly exceeding 8 meters.
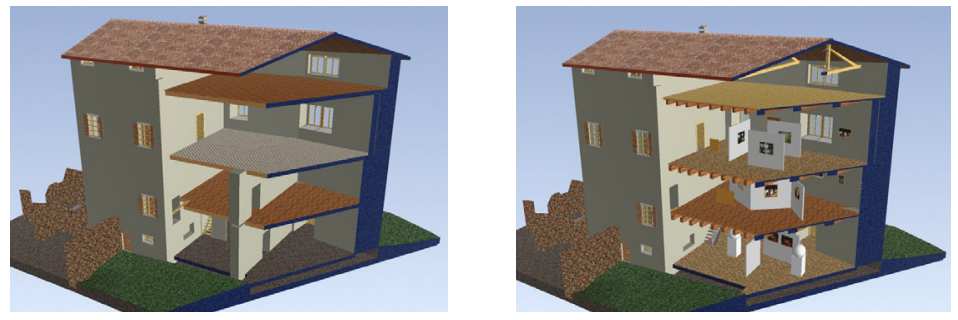

Figure 5: Cross section of the central portion showing the elimination of the internal wall on the two lower stories.

A wooden-reinforced concrete composite structure is adopted for the new floors, with steel connectors inserted in the wooden beam extrados by "dry" screwing. The beams are anchored to a continuous reinforced concrete beam with width equal to $2 / 3$ of the wall thickness.

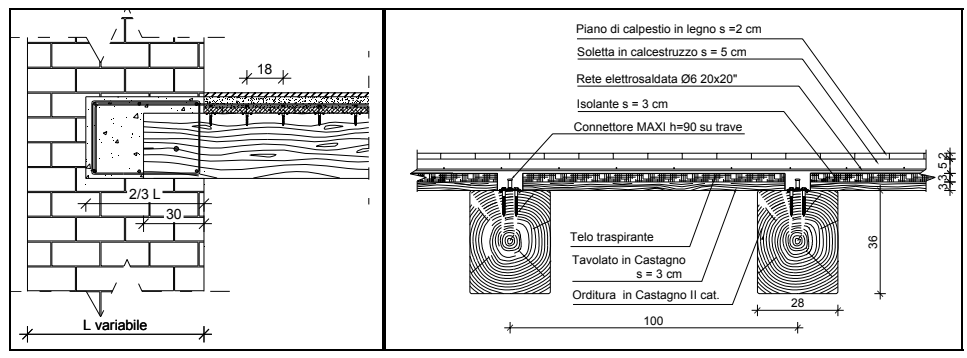

Figure 6: Structural details of the new wooden floors.

\section{Design seismic analysis of the building}

The castle is situated in seismic zone 1, according to the new classification of the Italian territory, characterised by a reference peak ground acceleration (PGA) of $0.35 \mathrm{~g}$. Moreover, due to the postulated use as a museum, a magnifying protection coefficient equal to 1.2 must be adopted. Then, a value of $0.42 \mathrm{~g}$ was introduced as resulting input PGA in calculations.

The basic level of the design seismic analyses performed on the rebuilt structure consisted in a "POR" spatial non-linear static approach, according to 
the updated version formulated in the new Italian seismic standards [1]. Nonlinear push-over analyses, and non-linear dynamic analyses developed by the methodology proposed in [2], were also carried out, so as to obtain more detailed information on local and global collapse mechanisms. The results of these enhanced steps of analysis, which substantially confirmed the safety levels evaluated by basic computations, will be presented in further communications on this study.

The structural model for the POR-like analysis, performed with a commercial software [3], is shown in Figure 7, where different colours are used to identify the different alignments of the walls. In order to correctly simulate the actual structural conditions of the building, its connections with the walls of the northern tower were also modelled in the analysis. In Figure 7, a typical forcedisplacement response diagram for a story (in particular, the first story for the analysis in the transversal direction), is also demonstratively reproduced. The structural verification is satisfied when, as shown in the graph, the maximum reactive force resulting from the contributions of all the panels at the examined level is greater than the corresponding story shear.
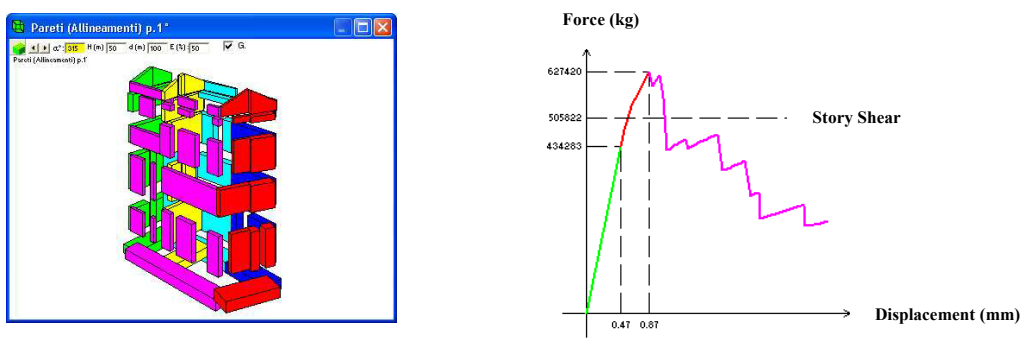

Figure 7: Structural model for the seismic analysis and typical response diagram of a building story.

\section{Base-isolated ground floor of the main exhibition hall}

\subsection{Design characteristics}

The ground floor design plan is drawn in Figure 8, where the positions of the two statues to be accommodated in the main exhibition hall, according to the new museum layout, are highlighted with red dots.

The solution adopted for the base isolation system consists in a steel floor supported by four high damping rubber bearings (HDRBs) and eleven steelTeflon sliders. All bearings are placed on top of short reinforced concrete columns built on the basement level, as shown in the rendering in Figure 9.

Figure 9 is a sketch of the building sequence of the floor, including the implementation of the fifteen short columns, the plot of the main steel beams, the installation of the secondary beams, and the casting of a top reinforced concrete slab over the supporting HI-bond corrugated steel sheet. 


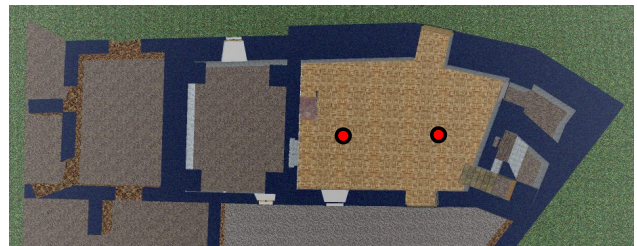

Figure 8: Design plan of the ground floor.
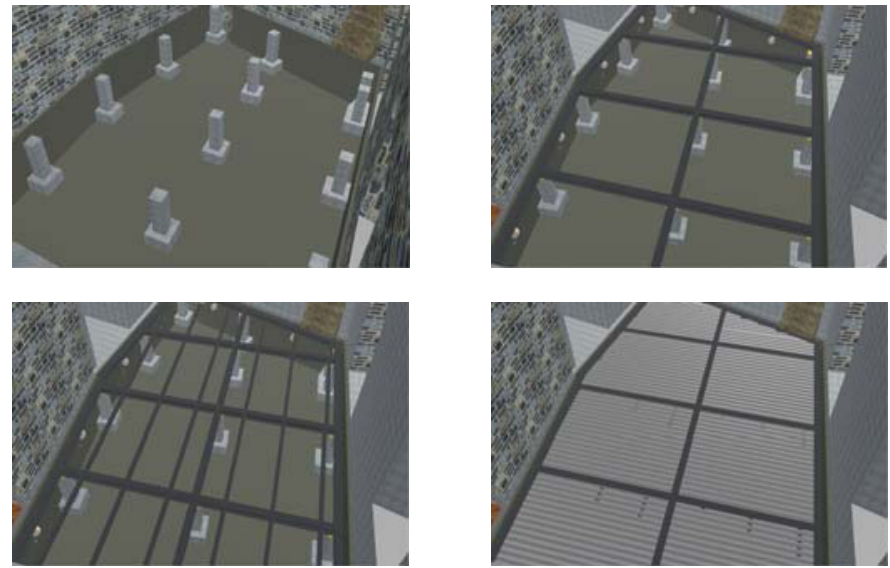

Figure 9: Construction steps of the base-isolated ground floor.

Two views of the basement level are reported in Figure 10, showing the main entrance and the complete volume created below the floor, to be used for the necessary inspection, check and maintenance activities of the isolation system.
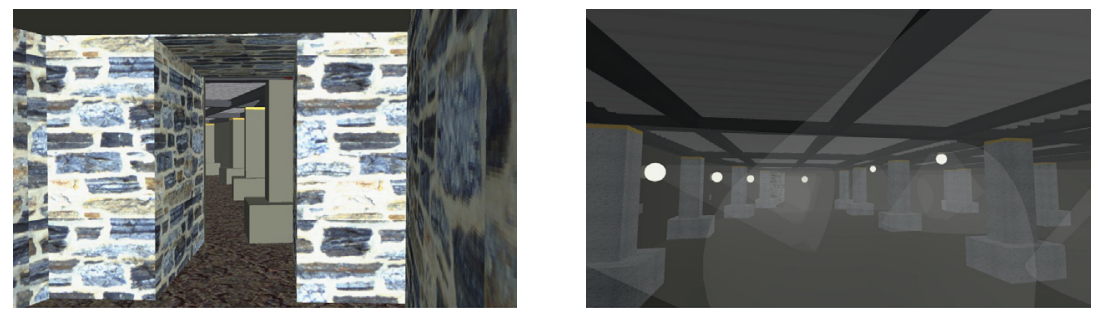

Figure 10: Views of the basement level.

The structural plan of the floor is drawn in Figure 11, whereas a detailed transversal section in proximity to a HDRB is offered in Figure 12. The groove introduced in the perimeter walls is aimed at offsetting the maximum floor displacements evaluated by the non-linear design analyses discussed in the next section. 


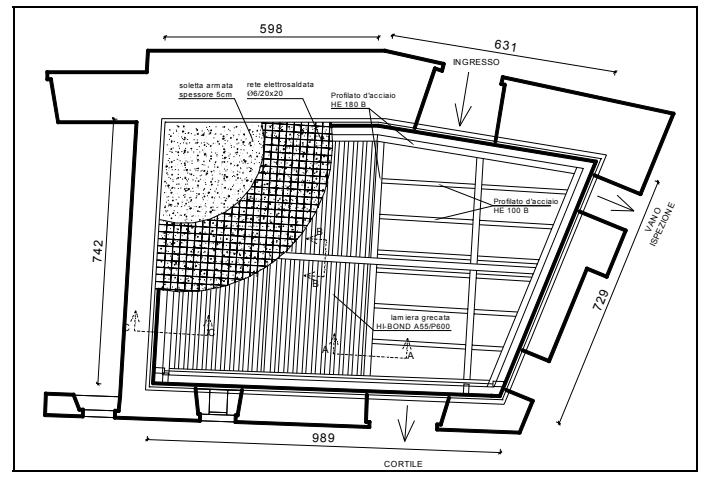

Figure 11: $\quad$ Structural plan of the ground floor.

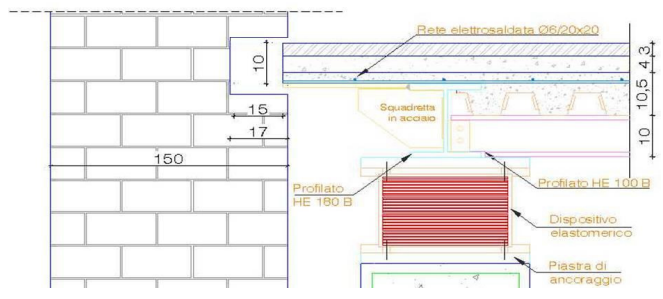

Figure 12: Detailed transversal section of the ground floor in correspondence with one of the four HDRBs.

Table 1: $\quad$ Characteristic parameters of HDRB isolators.

\begin{tabular}{|lc|}
\hline$H$ & $206 \mathrm{~mm}$ \\
\hline$D$ & $300 \mathrm{~mm}$ \\
\hline$t_{\mathrm{e}}$ & $120 \mathrm{~mm}$ \\
\hline$t_{\mathrm{i}}$ & $5.0 \mathrm{~mm}$ \\
\hline$t_{\mathrm{s}}$ & $2.0 \mathrm{~mm}$ \\
\hline$n_{1}$ & 24 \\
\hline$S_{1}$ & 15 \\
\hline$S_{2}$ & 2.5 \\
\hline$G_{\mathrm{dyn}}$ & $0.4 \mathrm{~N} / \mathrm{mm}^{2}$ \\
\hline$K_{\mathrm{e}}$ & $95.5 \mathrm{~N} / \mathrm{mm}$ \\
\hline
\end{tabular}

The four HDRB isolators have a total height $H$ of $206 \mathrm{~mm}$, top and bottom steel plates included, and a diameter $D$ of $300 \mathrm{~mm}$. The plates are squared in shape, with $380 \mathrm{~mm}$ long sides. The remaining geometrical parameters $\left(t_{\mathrm{e}}=\right.$ total rubber thickness; $t_{\mathrm{i}}=$ single rubber layer thickness; $t_{\mathrm{s}}=$ single steel layer thickness; $n_{1}=$ number of layers; $S_{1}=$ primary shape factor $=A^{\prime} / L$, where $A^{\prime}=$ steel layer net area; $S_{2}=$ secondary shape factor $=D / t_{\mathrm{e}}$ ) and mechanical parameters $\left(G_{\text {dyn }}=\right.$ dynamic modulus of elasticity; $K_{\mathrm{e}}=$ horizontal stiffness at 
$100 \%$ strain) are summed up in Table 1. All these quantities meet the requirements of the new Italian seismic Standards [1] for base-isolated buildings, except for $S_{2}$, which is slightly below the relevant lower limit (2.5 instead of 3). However, it should be considered that some exceptions are normally permitted for the base isolation systems of single structural or non-structural members, with respect to the limitations imposed to whole buildings.

The design of the protection system was aimed at reaching a vibration period of $2.5 \mathrm{~s}$ in isolated conditions. The equivalent viscous damping of the HDRB devices is equal to $10 \%$.

The steel-Teflon bearings act as pure sliders, with very low dynamic friction damping (below $2 \%$, for the normal pressures acting in this case study). They are composed of a bottom steel plate, a $5 \mathrm{~mm}$ thick lubricated Teflon disk, and a top steel plate, interfacing the Teflon disk by means of a $2 \mathrm{~mm}$ thick austenitic steel plate with a mirror finish. Further information on the mechanical properties and the experimental characterization of this type of sliders can be found in [4].

\subsection{Seismic design analyses and conclusive remarks}

The seismic design analyses on the isolated floor were carried out with a nonlinear dynamic approach. The finite element program SAP2000NL [5] was used for this numerical enquiry. Five artificial accelerograms generated from the response spectrum of Standards [1] were assumed as basic input. Five ground motion records derived from the main shock of the 1976 earthquake, scaled at the same modified PGA of $0.42 \mathrm{~g}$, were used to check the system performance in more detail. As a general result of this additional enquiry, the response to the historical records was always lower than the one induced by the artificial signals.

The finite element assemblage sketched in Figure 13 was adopted to model the response of the HDRB devices. It consists of two "gap", two "hook" and one "plastic Wen" non-linear link elements placed in parallel, which allow reproducing the typical four-branch hyper-elastic characteristic curve of rubber bearings. The steel-Teflon sliders were modelled by a "friction isolator" element, implemented in the basic library of the program, whose response is governed by the Coulomb friction law. The calibration of the relevant friction coefficient as a function of normal pressure and velocity, is also discussed in [4].

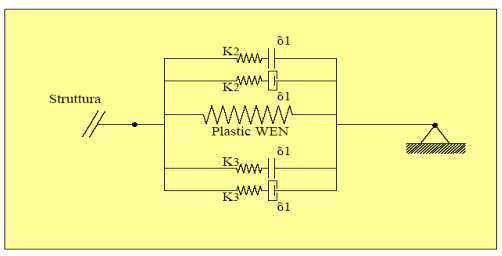

Figure 13: Finite element model of HDRB isolators.

The computational model of the base-isolated floor is shown in the left graph in Figure 14, where the positions of the HDRB isolators are highlighted with four small circles. The figure also illustrates the model of the two similar statues 
to be placed on the floor, constituted by a rigidly supported mass (with a $1.5 \mathrm{~m}$ height with respect to the base) where the total mass of the statue is concentrated, and a base anchored to the floor by a series of "gap" elements. The latter are introduced to simulate the rocking effects that may affect the response of the statues and their bases, beyond a certain input acceleration.
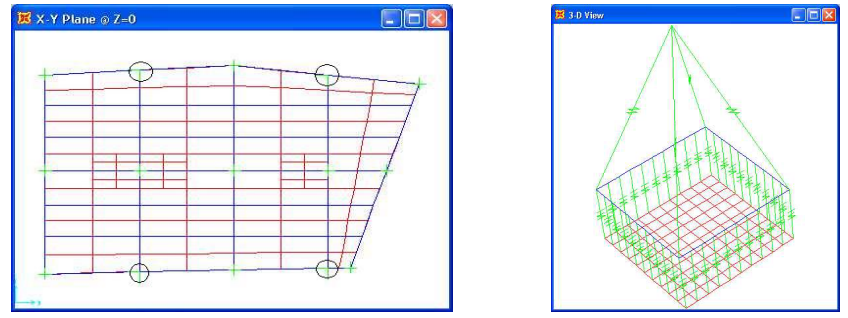

Figure 14: Computational models of the base-isolated floor and of a statue.
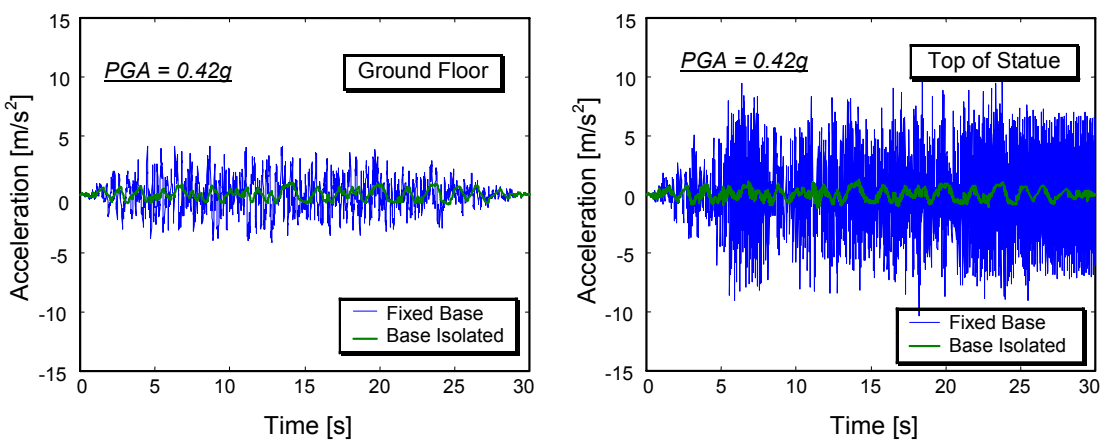

Figure 15: Response time-histories of the floor and a statue in fixed-base and base-isolated conditions.

A synthesis of the analyses performed is offered in Figure 15, where the response acceleration time-histories obtained from the most demanding of the five artificial accelerograms, for the ground floor and the top of one of the two statues, in base-isolated and fixed-base conditions, are plotted. The benefits induced by the protection system as compared to a conventional structural solution, are expressed by a fall in maximum response accelerations equal to 3.92 for the floor $\left(0.105 \mathrm{~m} / \mathrm{s}^{2}\right.$ instead of $\left.0.41 \mathrm{~m} / \mathrm{s}^{2}\right)$, and 7.53 for the statue $\left(1.36 \mathrm{~m} / \mathrm{s}^{2}\right.$ instead of $\left.10.25 \mathrm{~m} / \mathrm{s}^{2}\right)$, when passing from unprotected to protected configurations. As a consequence, the statues would be undamaged under the basic design earthquake, in base-isolated conditions, whereas they would collapse in the case of a fixed-base solution. Moreover, it is noted that, in the latter case, the first rocking of the bases of the statues would be attained at a 
PGA of only $0.13 \mathrm{~g}$, inducing a peak acceleration of $9.9 \mathrm{~m} / \mathrm{s}^{2}$ at the top of the statues. Such further unacceptably high value, which is shown by the timehistories in Figure 16, would require robust and ugly-looking anchoring of the bases to the floor. On the contrary, rocking is totally absent also far beyond the design PGA of $0.42 \mathrm{~g}$, in base-isolated conditions.

These results, although obtained through a simplified model of the statues and for a relatively small case study floor, outline new perspectives in the field of seismic protection of art exhibits in museum halls situated at the ground floor.

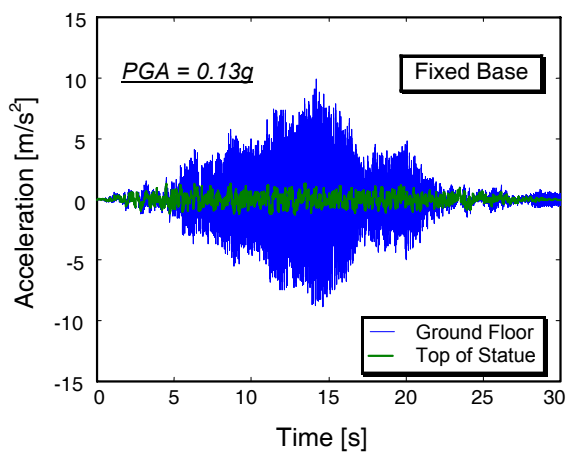

Figure 16: Response time-histories of the floor and a statue in fixed-base conditions at the PGA inducing the first rocking effects.

\section{References}

[1] O.P.C.M. 3431 (2005). Norme tecniche per il progetto, la valutazione e l'adeguamento sismico degli edifici. G.U. May $3^{\text {rd }}$, Rome, Italy.

[2] Sorace S., Terenzi G. (2002). Seismic evaluation and retrofit of historical churches. Structural Engineering International, IABSE, 12, 241-246

[3] Pugi F. (2006). Edifici in muratura e nuova normativa sismica. Alinea Editrice, Florence, Italy [in Italian].

[4] Sorace S., Terenzi G. (2005). Application of a combined base isolation/supplemental damping seismic protection strategy to a public building in Florence. International Conference "250th Anniversary of the 1755 Lisbon Earthquake”, LNEC Press, Lisbon, 481-486

[5] CSI (2006). SAP2000NL. Structural Analysis Programs - Theoretical and Users Manual. Version No. 10.10, CSI, Berkeley, CA. 